\title{
Performance Evaluation of Green Supply Chain of Textile and Apparel Industry in China
}

\author{
Zhengyan Shao \\ Business School \\ Beijing Institute of Fashion Technology \\ Beijing, China 100029
}

\begin{abstract}
Textile and apparel enterprises are facing the challenges of the changing consumer demand preferences and green trade barriers. Therefore, it is the strategic choice for them to enhance their international competitiveness and sustainable development capacity by establishing green supply chain (GSC) management system centering on the core enterprises and developing reasonable performance evaluation system to constantly monitor the operation of enterprises in the supply chain.
\end{abstract}

Keywords - textile and apparel industry; green supply chain; performance evaluation

\section{INTRODUCTION}

Philip Kotler, a famous American economist, once said, "The enterprises that only consider economic interests while ignoring long-term interests of consumers and society and those do not think highly of environmental protection will eventually be eliminated". As a pillar industry of the national economy, China's textile and apparel industry is currently facing environmental challenges. On the one hand, consumers' purchase behavior and preferences are influenced profoundly by the trend of green consumption. Consumers are placing increasingly higher demand on the safety and sanitation of textile and apparel industry, which makes green textile and apparel products the global consumption hot spot in the near future. On the other hand, after China's accession to WTO, the developed countries are gradually revoking the quota limit on China's textile and apparel products. Instead, they set green trade barriers for China's exports of textile products. Currently, there are three types of green trade barriers for textile products: one is the barrier against the products' negative impacts on consumers' safety and health. Such barriers are widespread and have significant influence. For example, due to the barrier set by Germany against 118 kinds of harmful azo dyes, $15 \%$ of China's textile industry faces obstructed export; the second is the barrier against the environmental impacts produced by textile products in the process from design and production to waste recycling; the third is the barrier to build the occupational health and safety management system. Under this situation, China's textile and apparel industry must proactively establish GSC management system targeting at the entire life cycle of

Fund: Science and technology project of Beijing Municipal Education Commission "Research on dynamic warning of financial distress in apparel industry based on integrated financial index" (AJ2017-12) textile and apparel products and strengthen its evaluation and monitoring. Only by doing so, the international competitiveness and sustainable development capacity of China's textile and apparel industry will be enhanced.

\section{LITERATURE REVIEW}

\section{A. The Organization of Green Supply Chain of the Textile and Apparel Industry}

The textile and apparel industry chain is composed of many links, including cotton planting, cotton spinning, weaving, knitting, yarn dyeing, post-treatment, fabric development, product design, clothing, technical detection, fabric and material testing, washing, printing and embroidery, branding, and marketing etc. as in "Fig. 1". The textile and apparel products have the characteristics of variability, short popular cycle, and timeliness. So the textile and apparel industry must be able to respond quickly to market signals [1]. Taking these characteristics into consideration, the enterprises having strong brands and marketing capabilities become the core enterprises in the entire industrial chain such as Nike and Adidas.

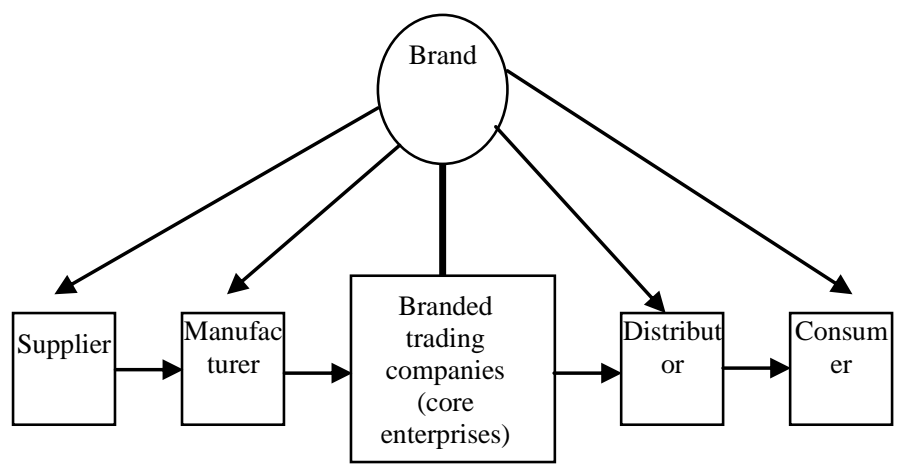

Fig. 1. Organizational pattern of green textile and apparel supply chain with core enterprises as the nexus.

Supply chain management is essentially the management of core enterprises. The textile and apparel industry is no exception. The green textile and apparel supply chain is built upon the core enterprises. As "Fig. 1" shows, the core enterprises link the upstream enterprises of cotton planting, spinning, apparel fabric production, and fabric dyeing with the downstream retailers and consumers to form an overall 
functional chain through the control of information flow, logistics, and capital flow, i.e. control of the process from fabrics procurement, clothing (production), and product delivery to consumers via the sales network.

\section{B. The Operation of Green Supply Chain of the Textile and Apparel Industry}

Compared with ordinary supply chain, the green textile and apparel supply chain has two additional processes i.e. raw material acquisition process and waste product recycling process. It changes the original linear supply chain pattern with raw material supplier as the starting point and consumer as terminal point into a pattern of closed-loop green supply chain [2]. In the green textile and apparel supply chain, the waste materials produced by any enterprise or sector must be recycled. This is also true for the expired products. The green textile and apparel supply chain has the raw material supplier as its starting point but no terminal point. If the waste textile products can still be used as fiber materials or half-finished products after recycling, the green textile supply chain is cyclical; when the waste products can be used as raw material for other products, the recycling process becomes the starting point for other supply chain; when the waste products have to be scrapped by burning, the recycling treatment is the terminal point of green textile supply chain [3]. The green textile and apparel supply chain aims for green production. The enterprises in the supply chain concentrate all their resources, technology, and energy on the enhancement of core competencies for green production and business. It guarantees not only green production in each link but also coordination of the entire supply chain; it produces green textile products at low cost. The logistics in green textile supply chain should be also "green"; its information flow contains a large amount of "green" information about green textile products. The core enterprises ensure the greenness of the member enterprises in the supply chain by reviewing, evaluating, and supervising the greenness of their production and products to finally achieve resources and energy efficiency and environmental and economic benefits simultaneously. "Fig. 2" shows the connections in the organizational pattern of the green textile and apparel supply chain.

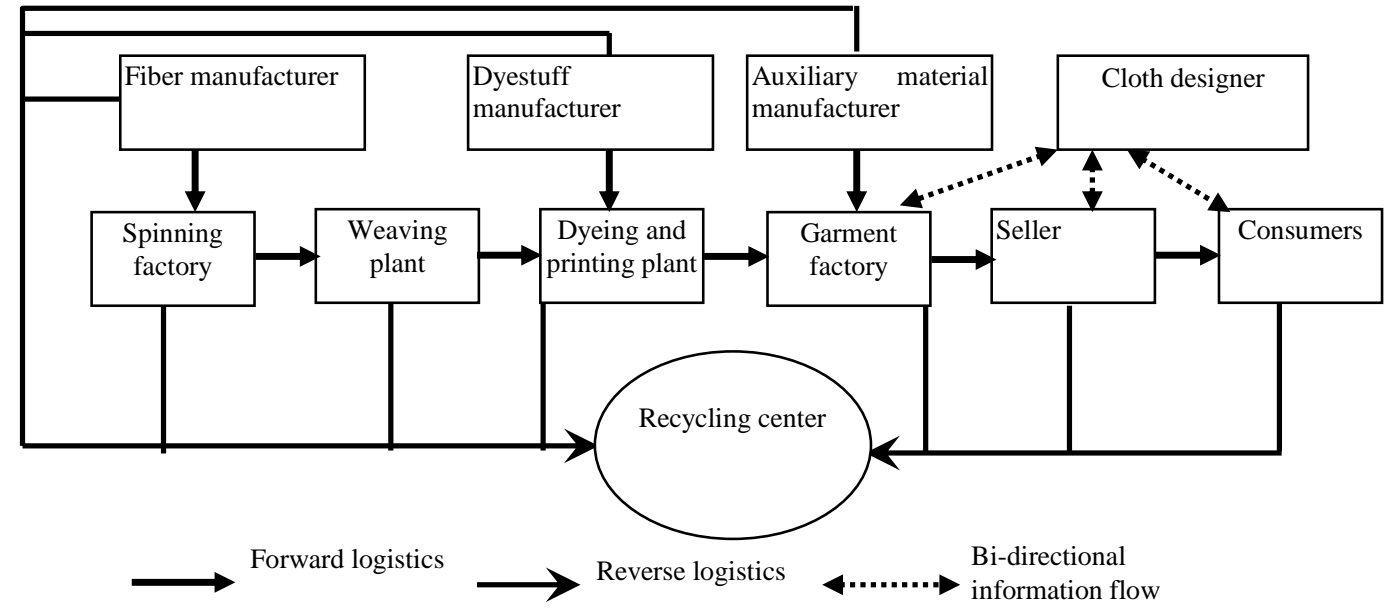

Fig. 2. Connections in the organizational pattern of the green textile and apparel supply chain.

\section{Performance Measurements of Green Supply Chain of the Textile and Apparel Industry}

Research on performance measurements and management of green supply chain has remarkably increased in the last ten years, due to the changing competitive nature from individual organizational competition to supply chains competing against each other [4]. As the environmental system and standards of developed countries are becoming increasingly strict in recent years, firms have understood that for competing in complex and continuously changing environment, it is compulsory to measure, monitor and manage organizational performance in its multiple dimensions. Measurement has been acknowledged as a crucial element to underpin improvement and the reporting of business performance. Research within this context largely focuses on the development of new metrics and frameworks, both qualitative and quantitative [5]. SupplyCain Council (2013) has proposed the most popular framework of integrated frameworks for measuring the performance of supply chains, which comprises five Key supply chain processes that are plan, source, make, deliver and return [6]. But this framework is not designed for a specific industry or an enterprise, and it can be developed over these five processes for the individual companies in the supply chain as well as for the entire network. Following this path of these literatures, the paper is aimed to explore performance measurement framework of green supply chain of the textile and apparel industry.

\section{MANAGEMENT OBJECTIVES OF THE GREEN SUPPLY CHAIN OF TEXTILE AND APPAREL}

There are three main objectives in establishing the green supply chain for the textile and apparel industry: environmental protection (targeting at the environmental system), optimal allocation of resources (targeting at the core enterprises and upstream and downstream enterprises in the supply chain) and increase of social welfare (targeting at the consumers) [7]. While applying GSC, the management and 
supervision objectives for textile and apparel industry should be established according to the above three major goals. Based on the characteristics of the textile and apparel enterprises, this study proposed several key points for supervision to promote the smooth running of China's green textile and apparel supply chain.

\section{A. To Minimize Environmental Pollution}

Based on the characteristics of China's green textile and apparel supply chain, the requirements for production and logistics are as follows:

- The acquisition of fiber, dyes, and supplementary material should be free from pollution and does not impact the environment either.

- To minimize environmental pollution caused by each link and achieve "non-pollution process".

- To consider the process for waste products treatment at the beginning of product design to eliminate (or reduce) environmental pollution.

- Transportation, storage and sales of raw materials, intermediate products and final products should produce no environmental pollution and are not polluted by the environment either.

- The usage and disposal process of products do no harm the human health or the environment.

- The textile machinery has less vibration, noise, leakage and is dust-proof.

\section{B. To Maximize the Utilization Efficiency of Resources and Energy}

To achieve the optimal allocation of resources and enhancement of economic benefits, the green textile and apparel supply chain must enhance the utilization efficiency of resources and energy. This requires that

- Raw materials or processes applied have the nature of less subsequent processes or convenient and simple subsequent processes, for example, color cotton fiber, as no dye is needed in its subsequent process.

- The process or technology applied is energy and resource-saving, for example, plasma printing technology which uses less water.

- The final textile products must be energy and resource-saving in usage, with stable properties. For example, the water, electricity, and detergent are saved when washing anti-fouling and washable clothes so that the cost related to sewage treatment can be reduced.

- Waste textile products can be recycled.

- To consider the energy consumption of the products in its use and disposal stages at the beginning of design, and develop the corresponding process to reduce the consumption.
Technical support is needed to meet these requirements: on the one hand, to strengthen the coordination between development, design and apparel production, e.g. develop and produce green fiber; make full use of the greenness of fiber to design green final products; develop and apply green dyes and additives; use high-efficiency and energy-saving textile machinery; develop and adopt high-efficiency, nonenergy-intensive process and technology, including fiber production, product processing, pollution treatment, and waste disposal technology. On the other hand, the establishment of internal and external information platform of the core enterprises should be strengthened. This requires the core enterprises to exchange and share information with the upstream and downstream enterprises in the supply chain. Only by doing so the production flexibility will be enhanced, the production and delivery of the upstream and downstream enterprises will be speeded up, inventory will be reduced, sales of products on market will be enhanced, and the overall performance of the entire supply chain will be improved.

\section{To Satisfy the Needs of Society}

To meet the requirements of consumers and to enhance the social welfare, the green textile and apparel supply chain is required to upgrade in the following aspects:

- The apparel fabrics must be safe and pollution-free to minimize the content of harmful substances such as formaldehyde and azo etc.;

- The flexibility for developing new products should be enhanced;

- The flexibility in terms of time for GSC's response to consumers' demand should be improved;

- Green packaging should be used to reduce resource consumption and increase customer value;

- Consumers' handling of warn and outdated clothes must be considered in GSC to enhance recycling and save money for the consumers.

\section{ESTABLISHMENT OF EVALUATION INDICATOR SYSTEM OF GREEN SUPPLY CHAIN OF THE TEXTILE AND APPAREL INDUSTRY}

In order to implement the management of GSC effectively, the enterprises must first conduct scientific and reasonable evaluation. Based on the organizational pattern of the green textile and apparel supply chain, the three objectives of GSC in terms of environmental, economic and social benefits should be considered. According to the key points for supervision, this study develops the overall performance evaluation system suitable for China's green textile and apparel supply chain, which comprises four firstlevel indicators, i.e. performance indicator of core enterprises, indicator of the level of customer service, indicator of the level of supply chain management, and indicator of the environmental protection level of the supply chain. As "Table I" shows, the four first-level indicators are classified into 34 secondary-level indicators. The above-mentioned indicators are explained briefly as follows. 
TABLE I. OVERAll Performance IndicAtor System for ChinA's GreEn TeXtile AND APParel Supply Chain

\begin{tabular}{|c|c|c|}
\hline $\begin{array}{l}\text { First-level indicator } \\
\text { (Objective layer) }\end{array}$ & $\begin{array}{c}\text { Property of the secondary indicators } \\
\text { (Criteria layer) }\end{array}$ & $\begin{array}{c}\begin{array}{c}\text { Secondary indicators } \\
\text { (Scheme layer) }\end{array} \\
\end{array}$ \\
\hline \multirow{8}{*}{$\begin{array}{l}\text { Performance of the } \\
\text { core enterprises }\end{array}$} & \multirow[t]{3}{*}{ Profitability } & Production and sales rate \\
\hline & & Profit-to-sales ratio \\
\hline & & Return on net assets \\
\hline & \multirow[t]{2}{*}{ Growth potential } & Growth rate of sales \\
\hline & & Growth rate of profit \\
\hline & \multirow[t]{3}{*}{ Operational capacity } & Cash turnover days \\
\hline & & Inventory turnover days \\
\hline & & Quick ratio \\
\hline \multirow{6}{*}{$\begin{array}{c}\text { Customer service } \\
\text { level }\end{array}$} & \multirow{3}{*}{ Service conditions } & Customer satisfaction \\
\hline & & Fulfillment rate of customer order \\
\hline & & Waiting time of customer order \\
\hline & \multirow[t]{3}{*}{ Market response } & Market share \\
\hline & & Customer retention \\
\hline & & Growth rate of new customers \\
\hline \multirow{12}{*}{$\begin{array}{l}\text { Level of supply chain } \\
\text { management }\end{array}$} & \multirow{7}{*}{$\begin{array}{l}\text { Coordination of core enterprises with the } \\
\text { node enterprises in the supply chain }\end{array}$} & Cycle of order completion \\
\hline & & On-time delivery rate \\
\hline & & Qualification rate \\
\hline & & Frequency of information exchange \\
\hline & & Quality of information transfer \\
\hline & & Flexibility of yield of the supply chain \\
\hline & & Flexibility of products of the supply chain \\
\hline & \multirow{5}{*}{$\begin{array}{c}\text { Overall cost-effectiveness of the supply } \\
\text { chain }\end{array}$} & Overall inventory cost of the supply chain \\
\hline & & Overall transportation cost of the supply chain \\
\hline & & Overall information development and maintenance cost of the supply chain \\
\hline & & Productive capacity utilization rate of the supply chain \\
\hline & & Added value rate of production of the supply chain \\
\hline \multirow{8}{*}{$\begin{array}{c}\text { Environmental } \\
\text { protection level of the } \\
\text { supply chain }\end{array}$} & \multirow[t]{3}{*}{ Environmental carrying capacity } & Quantity of discharged toxic wastes \\
\hline & & Energy consumption per unit of output \\
\hline & & Resources consumption per unit of output \\
\hline & \multirow[t]{2}{*}{ Environmental quality cost } & Environmental maintenance cost \\
\hline & & Environmental damage cost \\
\hline & \multirow[t]{3}{*}{ Degree of recycling and public recognition } & Re-utilization rate of raw materials and energy \\
\hline & & Return rate on waste product recycling \\
\hline & & Customers' recognition degree of the greenness of products \\
\hline
\end{tabular}

\section{A. Performance Indicator of Core Enterprises}

This indicator reflects the economic benefits that GSC brings directly to the core enterprises. It is the source power for the implementation and development of GSC. The performance indicator of the core enterprises are decomposed into three aspects i.e. profitability, growth potential, and operational capacity, which reflects the economic development status of the enterprises.

The secondary indicators that reflect the enterprises' profitability are production and sales rate, profit to sales ratio, and return on net assets. The higher the values of these indicators, the better the financial status of the core enterprise and the more competitive the GSC is. The secondary indicators that reflect the growth potential of the enterprises include growth rate of sales and profit growth rate. The higher the values of these indicators are, the better the development of GSC of the core enterprises is. The secondary indicators reflecting the operational capacity of the enterprises are cash turnover days, inventory turnover days, and quick ratio. When the cash turnover days and inventory turnover days are short and the quick ratio remains as 1:1, the core enterprises maintain a good partnership with the enterprises in the supply chain, and have high management level of assets.

\section{B. Indicator of the Customer Service Level}

This indicator characterizes the added value that GSC management brings to end customers. It reflects the overall competitiveness of the textile and apparel industry through the implementation of GSC. In this study, the customer service level is evaluated from two perspectives i.e. service conditions and market response.

The secondary indicators that reflect the service conditions of textile and apparel industry include customer satisfaction, fulfillment rate of customer order, and waiting time of customer order. The value of customer satisfaction indicator can be obtained through customer visits and statistics of customers' feedback.

Indicator of fulfillment of customer order is the ratio of the number of fulfilled orders to that of total customer orders. The higher the customer satisfaction, the more fulfilled the orders are, which indicates a high level of credibility and service quality of the GSC. Waiting time of customer order refers to the time taken by enterprises to deliver the products to customers after customers make the orders. The shorter the waiting time of customer, the quicker the GSC responds to customers' demands. The secondary indicators reflecting the market response of the green textile and apparel supply chain include market share, customer retention, and growth 
rate of new customers. Market share indicator reflects the market's loyalty and preference to the products supplied by GSC. Customer retention and new customer growth rate indicators reflect the degree of recognition and dependence of customers on the enterprises. The higher the market share, customer retention and new customer growth rate, the better popularity and reputation the products have; the higher the degree of monopoly of the GSC is, the higher the degree of dependence of the market on the products is.

\section{Indicator of the Level of the Supply Chain Management}

Management level indicator reflects the overall operation status of the GSC centering on the core enterprises. In this study, the management level of China's green textile and apparel supply chain is evaluated from two aspects i.e. coordination of core enterprises with the node enterprises in the supply chain and the overall cost-effectiveness of the supply chain. The secondary indicators reflecting the coordination of core enterprises with the node enterprises in the supply chain include cycle of order completion, on-time delivery rate, qualification rate, frequency of information exchanges, quality of information transfer, flexibility of the output of the supply chain, and flexibility of products of the supply chain. Cycle of order completion refers to the time taken from customer making the order and the upstream and downstream enterprise's arranging and completing the production tasks to the delivery of the product to customer; on-time delivery rate refers to the percentage of the order completed on time by enterprises in the GSC as required by customer; qualification rate refers to the percentage of qualified output completed by enterprises as required by the customer; frequency of information exchanges refers to the number of browsing of or replying to enterprises' information by other enterprises in the GSC; quality of information transfer can be measured by the accuracy and timeliness of information transfer; flexibility of output of the supply chain includes the flexibility upwards and the flexibility downwards. The flexibility upwards means the flexibility of output supply of the manufacturer and it can be measured by the number of days needed for increasing the output by $20 \%$ in the absence of prior plans. The flexibility downwards means the flexibility of product supply of the dealer and it can be measured by the percentage of reduction of the order delivered in advance within 30 days under the condition of no inventories or losses; flexibility of the products of supply chain refers to the ability of the enterprises in GSC to deal with the changes of product demand. It can be measured by the number of days needed to produce new products in the absence of prior plans. These secondary indicators are used to measure the coordination of core enterprise with the node enterprises in GSC from four perspectives i.e. product delivery, product quality, information sharing, and flexibility of business processes.

The secondary indicators that reflect the overall costeffectiveness of the supply chain include overall inventory cost of the supply chain, overall transportation cost, overall information development and maintenance cost, productive capacity utilization rate, and added value rate of production. Three secondary indicators i.e. overall inventory cost, overall transportation cost, and overall information development and maintenance cost are used to measure the inventory cost, transportation cost, and information cost of the GSC, respectively. Productive capacity utilization rate of the supply chain refers to the ratio of average turnover rate of business process to the theoretical turnover rate. It reflects the production capacity and utilization rate of the overall GSC; the added value rate of production means the ratio of the value created by GSC to the cost it pays. High productive capacity utilization rate and high added value rate of production of the supply chain indicate that the green textile and apparel supply chain has strong added value creation capacity and high management level.

\section{Indicator of the Level of Environmental Protection}

Indicator of the environmental protection level is the key indicator for the evaluation of the overall performance of GSC. In this study, environmental protection level of GSC is evaluated from three aspects i.e. environmental carrying capacity, environmental quality cost, and degree of recycling and public recognition. The secondary indicators reflecting the environmental carrying capacity include quantity of discharged toxic wastes, energy consumption per unit of output, and resource consumption per unit of output. The quantity of discharged toxic wastes can be obtained from the cumulative sum of the quantity of wastes discharged within a certain assessment period. The energy and resource consumption per unit of output is obtained by taking all the enterprises in the green supply chain as a whole. The secondary indicators reflecting the environmental quality cost are environmental maintenance cost and environmental damage cost. Environmental maintenance cost occurs before the occurrence of environmental damage which includes environmental damage prevention cost and environmental monitoring cost. Environmental damage cost occurs after the occurrence of damage to the environment, including internal environmental damage cost and external environmental damage cost. For example, the pollution control cost of enterprises after pollution occurs and the fine for environmental damage of enterprises all belong to environmental damage cost. The secondary indicators reflecting the degree of recycling and public recognition include re-utilization rate of raw materials and energy, degree of waste product recycling, and customers' recognition degree of the greenness of the products. Reutilization rate of raw materials and energy means the reutilization degree of the consumed raw materials and energy. The higher the rate, the better the raw materials and energy can be re-utilized; return rate on waste product recycling reflects the benefit of product recycling. If the rate is negative, it means that the cost of product recycling exceeds the benefit; if the rate is positive, then the benefits are generated by product recycling; the higher the rate, the better the product recycling is. 


\section{PERFORMANCE EVAluation Methods OF} EVALUATION INDICATOR SYSTEM OF GREEN SUPPLY CHAIN OF THE TEXTILE AND APPAREL INDUSTRY

In the process of application of performance evaluation methods of evaluation indicator system of green supply chain of the textile and apparel industry, two questions should be considered: the determination of the index weight and the measurement of the index value.

\section{A. Determination of the Weight of Each Indicator}

Different textile and apparel enterprises have different operation environment and pay various degree of attention to different indicators. In addition, the enterprise may shift the management focuses at different development stages. Therefore, the weight of each indicator will be different for different enterprises, at different stages, and under different conditions. The AHP method is adopted to determine the weight of each indicator. When using this method, the evaluator is required to develop the importance scale for pair wise comparison by referring to the function table of relative importance. This method reflects the will of the evaluator and is highly valid with small errors. The calculation process in detail can be found in literatures.

\section{B. Calculation of Indicator Value}

Calculation of indicator value is the key for the performance evaluation of the GSC. The evaluator can collect information from the financial report and internal and external management data of the enterprise to calculate the value of each secondary indicator. Then the evaluator can employ linear interpolation method to perform the nondimensionalization treatment to each indicator, calculated by hundred mark system. The specific process is as follows: when the indicator is positive, the higher the value, the better. The upper effect measure is used. The formula is as follows:

$$
X_{i}=u+\frac{P_{i}-P_{\text {min }}}{P_{\text {max }}-P_{\text {min }}} \times(v-u)
$$

When the indicator is negative, the lower, the better, and the lower effect measure is used. The formula is expressed as follows:

$$
X_{i}=u+\frac{P_{\text {max }}-P_{\mathrm{i}}}{P_{\text {max }}-P_{\text {min }}} \times(v-u)
$$

In Formula 1 and Formula 2:

$X_{i}$ is a specific evaluation indicator;

$P_{i}$ refers to the enterprise's original data corresponding to the indicators.

$P_{\max }$ is the maximum value allowed for the evaluation indicator:
$P_{\min }$ is the minimum value allowed for the evaluation indicator;

$u$ is the lower limit for the indicator value, and $u=60$ is taken;

$v$ is the ceiling for the indicator value and $v=100$ is taken.

\section{Comprehensive Evaluation and Scoring}

The weight of each evaluation indicator is calculated according to the weights in the criteria layer composed of the attributes and weights of the secondary indicators to finally obtain the performance evaluation value of China's green textile and apparel supply chain.

$\sum$

The performance of green supply chain management $=$ (3)

By using weighted comprehensive evaluation method for China's textile and apparel industry, the assessment value of overall performance of the GSC can be obtained. Relevant information can be also obtained concerning the performance of core enterprises, customer service level, supply chain management level, and environmental protection level. This provides the scientific and reasonable basis for enterprises to improve the supply chain management and strengthen local monitoring and control.

\section{CONCLUSION}

It is the requirement of the era for textile and apparel enterprises to shift from the traditional production mode to green and clean production mode. It is also the inevitable choice for the enterprises to enhance the competitiveness. To achieve this, the core enterprises must establish the green supply chain. In addition, under the leadership of the core enterprises, the management objectives of the supply chain must be made clear and the effective performance evaluation system be established. After implementing GSC, the core enterprises must manage the supply chain effectively and regularly evaluate the enterprises in the supply chain. They must give the results and feedbacks to the enterprises for their continuous improvement to achieve economic, environmental and social benefits.

\section{REFERENCES}

[1] Deng Ruchun.Supply chain management of Textile and Apparel Industry [M].China Textile Press,2005

[2] Wu Dichong. Study on Supply Chain of Green Textile [J]. Silk, 2004(12): 1-3.

[3] Wang Yingluo, Wang Nengmin. The Basic Principle of Green Supply Chain Management [J]. China Engineering, 2003, (5) : 82-87.

[4] Li Shujuan. Study on Performance Evaluation of Supply Chain [J]. Value Engineering, 2005(12): 48-52.

[5] Zhu Qinghua, Zhao Qinghua. A Review on the Study of Green Supply Chain Management and Corporate Performance Evaluation [J]. Research Management, 2005(7):93-98. 
[6] Taticchi, Paolo, F. Tonelli, and R. Pasqualino. Performance measurement of sustainable supply chains: A literature review and a research agenda[J]. International Journal of Productivity \& Performance Management 62.8(2013):782-804, 2013.

[7] Carter, Craig R., and D. S. Rogers. "A framework of sustainable supply chain management: moving toward new theory." International Journal of Physical Distribution \& Logistics Management 38.5(2008):360-387. 